\title{
From Social Worker to Social Worker: MSW Mentorship Outcomes
}

\author{
Jessica Nestelroad $^{1} \&$ Wendy Ashley ${ }^{2}$ \\ ${ }^{1}$ Department of Children and Family Services, California State University Northridge, Northridge, USA \\ ${ }^{2}$ California State University Northridge, Northridge, USA \\ Correspondence: Wendy Ashley, Psy.D, LCSW, California State University Northridge, 18111 Nordhoff Street, \\ Northridge, CA 91330-8226, USA. Tel: 310-200-3932.
}

Received: January 19, 2019

Accepted: February 8, 2019

Online Published: February 13, 2019

doi:10.5430/irhe.v4n1p1

URL: https://doi.org/10.5430/irhe.v4n1p1

\begin{abstract}
Students returning to graduate school after years in the workforce face multiple challenges, including reviving dormant academic skills, juggling multiple roles and role alterations, and navigating academic structures and procedures. Department of Children and Family Services (DCFS) Children's Social Workers (CSW's) returning to school to obtain a Masters in Social Work (MSW) degree face additional unique challenges, including graduate level writing expectations, learning to be a professional social worker as dictated by the standards of the discipline, and making a paradigm shift from social work employee to social work student. A mentoring project was developed to assist students employed as CSW's in successfully transitioning from employee to MSW student, and aimed to strengthen the public child welfare employee students to ensure that they are better equipped to successfully achieve their MSW, develop strategies to effectively integrate their skills into the DCFS system following graduation and ultimately increase proficiency to effectively serve vulnerable children and families. The purpose of this research study is to explore how the implementation of a mentorship program for CSW's obtaining an MSW contributed to professional success post-graduation, when social workers returned to their positions with DCFS. This qualitative study was developed using detailed oral interviews with five participants. This research reveals mentorship programs can be both personally and professionally successful, identifying needs germane to this population of students and suggesting a specialized approach to educating current CSW's to cultivate the skills essential for effective social work practice.
\end{abstract}

Keywords: social work, mentorship, professionalism, graduate education

\section{Introduction}

Research reflects the accelerated efforts over the past 15 years to re-professionalize public child welfare and increase competence in the child welfare field (Perry, 2006). As a result, considerable federal monies, state funds and multiple resources have been invested in the development of specialized curriculum for students willing to commit to service in a child welfare setting following attainment of their MSW degrees. Professional education and training result in favorable outcomes for child welfare: agencies obtain an educated, credentialed workforce with high retention rates, employees report high job satisfaction and employees are equipped with a level of competence and understanding of the public child welfare system (Whitaker \& Clark, 2016).

To maintain the title of Children's Social Worker (CSW) in most County Child Welfare Agencies, individuals must have obtained a bachelor's degree from a four-year college. The degree does not have to be in social work or a related counseling type field. If CSW's decide to return to school to obtain a master's degree, it can be many years later and they are likely to face unforeseen challenges that are difficult to overcome (Hall \& Sudol, 1991). For these students, additional academic and professional support may prove both useful and necessary to encourage student acclimation and success.

Students transitioning from public child welfare employees to students in an MSW program face multiple unique challenges. One of the primary concerns is in regards to writing. Many have mastered the writing expectations for their positions, which differ significantly from the research, APA expectations and critical thinking inherent in a rigorous master's program. Another challenge is in the paradigm shift from social work as a position to social work as a discipline, which is essential for success in an MSW program. Because they already hold the Social Worker title, these students have the task of separating themselves from their role as an employee to allow them to embrace the 
role of student. The role of a CSW is one with considerable authority, where poor decisions can result in continued abuse, trauma or death. Cultivating a professional sense of self and learning the ethics of a profession within a context of a job description where the consequences are dire is challenging at best.

\section{Literature Review}

Since the late 1980's, universities have seen an increase in numbers of adult learners, both those that are attending college for the first time, and those who are re-entering college after a period of working as professionals (Home, 1998). Older adult students have different needs and challenges than younger adult students, a dilemma not all universities and colleges have adequately addressed (Home, 1998). In particular, older women students have specific stressors and challenges that differ from older male students. Social workers, especially child welfare workers, are by and large women, indicating specific needs for this population of professionals returning to school for advanced degrees (The Social Work Gender Gap - MSW Careers, 2016).

CSW's working at County Child Welfare Agencies who enroll as students in MSW programs often struggle in different ways than a 'traditional' graduate student (Hall \& Sudol, 1991). Writing at a graduate level, making a paradigm shift from social work employee to social work student, and learning how to be a professional social worker as dictated by the standards of the discipline are unique challenges to this population (Michaud, 2011). Additional factors such as age, income, cohort connectedness, and application of life experiences to the classroom environment, all add complexity to their adjustment (Hall \& Sudol, 1991).

\subsection{Challenges for Students Re-entering Academic Environments}

The transition from professional employee to Master's level student can be a monumental endeavor. Students may face internal and interpersonal challenges, which may include: giving up some of their income and the fulfillment associated with a career; school demands that go beyond the typical workday hours and interfere with family or social activities; a lack of connection with younger students due to an age gap; developing dormant academic skills which haven't been used for years; a feeling of urgency that isn't shared by younger students; and a lack of academic acknowledgement for experience and skills gained in the professional world (Bauer \& Mott, 1990; Gigliotti \& Huff, 1995; Hall \& Sudol, 1991).

An additional challenge is in shifting from a professional identity as a social worker to the role of a social work learner. One of the main areas of concern for these students is their writing abilities, where many have mastered the writing expectations for their employed positions, which differ significantly from the requirements from a rigorous master's program (Michaud, 2011). Academic writing, study skills, and reading to understand large amounts of educational material are some of the skills that aren't required for most careers but are necessary for academic success in higher education (Michaud, 2011).

One major hurdle for an older adult student is not being credited for their real-life experience and the skills they have learned in the workplace. Academic programs are structured to meet the needs of first-time college students without much lived or academic experience. Because of these challenges, older adult students are more likely than younger adult students to drop out of college after their first year back in school (Cleary, 2012).

Similarly, older students face barriers with traditional college writing instruction, which is designed for young adults entering college for the first time. Older students who may be confident and successful in the workplace can feel uneasy and unprepared as graduate school writers (Michaud, 2011). This type of writing instruction doesn't take into account the experiential knowledge of older students and thus fails to recognize that the experiential knowledge held by adult students increases their confidence and can be used to connect new knowledge with what they already know (Cleary, 2012). Not valuing and encouraging the older student to incorporate their experiential knowledge can lead to low self-esteem and a sense of not belonging (Fleming \& Murphy, 2000).

\subsection{Challenges for Women Re-entering College Environments}

Women who are re-entering college face three types of barriers: situational, institutional, and dispositional. Situational barriers include finances and family responsibilities (Westervelt, 1975). Lower-income women and women with young children have higher situational barriers than women who have more income and no young children. Institutional barriers include the lack of evening classes and financial aid as well as the rigidity of academic procedures and degree requirements. Dispositional barriers reflect the personality and attitude of the individual student and their willingness and ability to overcome the obstacles they may face while in obtaining further higher education. Women are more likely than men to delay education until they reach the middle years of life in order to allow for their children to grow up and move on (Westervelt, 1975). 
Age is often a factor in how women experience academic re-entry challenges. A woman re-entering as a student with a young family may experience role conflict due to the competing demands of her family and school responsibilities, while an older woman re-entry student may experience role conflict when going to school and continuing employment. Home (1998) describes these role conflicts as role overload, role conflict and role contagion. Role overload occurs when women re-entering into school have multiple responsibilities and inadequate time to accomplish each of these roles successfully, leading to frustration. These women and their families may assume that student will be willing or able to add additional academic responsibilities without altering or decreasing family obligations.Some families may have a lack of understanding when the student requests family members take over some of her roles or responsibilities (Miller \& Padula, 1999). Older female students may end up feeling isolated and like no one truly understands their heavy load of responsibilities, except possibly the other women who have re-entered academia with her (Miller \& Padula, 1999).

Role conflict occurs when the multiple responsibilities of the re-entering students compete for priority, leading to feeling overwhelmed and exhausted (Gigliotto \& Huff, 1995; Miller \& Padula, 1999; Stoecker, 1991). Constantly juggling the demands of school, family, work, and friends (each insisting that they should have priority over the other areas), while trying to please everyone is an almost impossible task, and trying to meet these demands can cause exhaustion, frustration, and anger. However, role conflict can be a positive experience if the woman's family is willing to discuss the changing roles within the family unit and take on new or additional responsibilities (Miller \& Padula, 1999).

Role contagion occurs when a woman is preoccupied with one role while performing another, for example, being at work while trying to deal with family responsibilities is an example of role contagion (Home, 1998). This type of multi-tasking may result in failing to meet either or both responsibilities, leading to chaos within the family system and a failure to meet work expectations. Full-time students and students caring for elderly, ill or disabled family members have been found to be the most likely to experience role contagion (Home, 1998).

\subsection{Child Welfare Social Workers}

Being a CSW is a difficult task and the role involves dealing with high levels of uncertainty, danger, and emotion (Barth, et al, 2008). While working to protect children from abuse, neglect and trauma, CSW's must also balance the responsibility of ensuring physical, psychological and emotional health and well-being. The work of a CSW is extremely important but conditions are often not ideal, with ongoing challenges that include low wages, large caseloads, heavy bureaucracy, poor working environments, high staff turnover, incomplete training, and inadequate supervision (Barth, et al, 2008).

Making the transition from social work employee to social work student can be significantly stressful. One of the goals of graduate professional education is the development of professional identity, by instilling the professions' relevant value system in each student (Manzo \& Ross-Gordon, 1993). This socialization - the process in which a person who seeks to belong to a certain group obtains the values, attitudes, behaviors, and acceptance of that group is necessary for success in the new role of a graduate student. While CSW's obtaining MSW's are attempting to engage in socialization with the academic perspective of a social worker, they are likely to also experience loss. One consequence of the transition to graduate school is a loss of social status, meaning lower income and/or the loss of status from leaving a career, even temporarily. This position transition is perceived as stressful and challenging because the certainty of one's place in a professional hierarchy has been replaced by the uncertainty often associated with being a novice academic scholar and researcher (Stoecker, 1991; Watts, 2009).

Child welfare social workers returning to MSW programs are often challenged by graduate level writing standards. Although older adult students have already participated in a range of personal and professional experiences outside of academia where they likely had to utilize effective written communication skills, using these existing skills in relation to graduate level writing can feel overwhelming (Michaud, 2011). Learning to write in a scholarly rather than professional manner requires practice and is compounded by the expectation for increased critical thinking skills. Fortunately, however, some older adult students do have a strong motivation for obtaining the needed skills and can quickly establish competency to the level needed to excel (Gillam, 1991; Watts, 2009).

\subsection{Mentorship Programs for Improving Student Experiences}

Outcomes from mentorship programs are often based upon both the mentee's voluntary involvement and the mentor's participation while interacting with the mentee (Allen, Eby \& Lentz, 2006). Efficacy in mentoring often includes evaluation of perceived input into the mentoring process and training perceived as high in quality, which are consistently related to outcome variables (Allen, Eby \& Lentz, 2006). Because many mentoring programs are 
developed based on distinct needs, participation is mandatory, potentially impacting the factors that ensure mentorship success. As a result, some mentoring theories advocate for formal mentoring programs to be designed to simulate an informal mentoring process, allowing for both the mentees and mentors to participate voluntarily (Allen, Eby \& Lentz, 2006).

Both mentees and mentors who believe that their participation was forced may be less motivated and may regret their involvement in the program. This may contribute to behavior that is ineffective such as neglect of the mentee, or even the mentee being resistant to learning from the mentor (Allen, Eby \& Lentz, 2006). Allowing mentors and mentees to have a voice in the matching process might encourage investment in the relationship before the mentorship program actually starts to take place. Consequently, both individuals are likely to feel a greater motivation to utilize the relationship to its full potential. This greater involvement might explain why perceived input into the matching process appears to be a major component of implementing an effective formal mentoring practice (Allen, Eby \& Lentz, 2006).

\section{Aims and Objectives}

The purpose of this research study is to explore how the implementation of a mentorship program for County Child Welfare Social Workers obtaining an MSW contributed to professional success post-graduation, upon resuming their professional positions. The data collected may be used to reformat various mentorship programs to better benefit County Child Welfare Social Workers who are obtaining their MSW degree and improve the long term impact and efficacy of mentorship programs for this population.

Within the Master of Social Work (MSW) department at California State University, Northridge (CSUN), students who were simultaneously employed by a County Child Welfare Agency as a CSW and pursuing their Master's degree in Social Work were identified and asked to participate in a mentorship program designed to support CSW's returning to higher education. These individuals were given a pre-test, multiple mid-tests, and a post-test that consisted of several closed-ended survey questions. Although the data showed the mentorship program was helpful for the majority of the graduating participants, a qualitative component allowing the participants to expound upon their experiences was not included in the initial study. As such, the perspectives the participants held of the program were limited to the quantitative data. This study adds a qualitative component to the existing data, allowing for their individual narratives to be heard.

\section{Methodology}

\subsection{Participants}

In order to participate in this study, each individual must have also been a participant in a previous research study evaluating a mentorship program for CSW's administered by the social work department at the California State University, Northridge (CSUN) campus over the span of one academic year. Participants were identified as eligible upon entry into the MSW program, and then were offered the opportunity to join into the mentorship program. No other individuals were considered for this research. Within the original study, participants engaged in a mentorship program once a week before their classes with faculty members leading the groups.

Participants from the original study were contacted to inquire if they were interested in providing qualitative information regarding the mentorship program via a 20-50 minute interview. Of the 22 original participants, nine expressed willingness to participate in the current study and were contacted to obtain formal consent and schedule interviews. Five individual interviews were conducted with mentorship project participants graduating from CSUN's MSW program between the years of 2014 and 2017.

The participants were varied in cultural backgrounds; two identified as Latino/a, one identified as Sri Lankan, one identified as Puerto Rican and one identified as Black/African American. Two participants were male and three were female. The average age of the participants was 36 . All graduated within five years of the current study.

\subsection{Measures}

Interviews were conducted to gauge the perceived outcomes and effectiveness of the mentorship program for County Child Welfare workers returning to graduate school to obtain an MSW. The interviews focused on two primary areas: experience in the mentorship program and post-graduation impact. Participants were invited to share their perspectives on what content from the program was valuable and what information, skills and experiences they felt were beneficial and transferrable to their jobs post-graduation. All original participants were contacted via email and invited to participate in the study. Nine participants responded to the initial request, with five participants scheduling a time to meet for an interview $(n=5)$. 


\subsection{Research Design}

This project was constructed as a qualitative study, utilizing a narrative design to add open-ended questions to the original quantitatively focused research project. We approached this research using a qualitative interpretive method (Elliott, 1999) to seek out the narratives, voices and experiences of public child welfare workers who participated in the mentorship program. These narratives were especially important for gaining access to the post graduate experiences of these social workers, their feelings and thoughts about the effectiveness of mentorship, and the meaning and internalization of their unique educational experiences. The following data include narratives, themes and quotes from participants as they reflected on the value of the mentorship program and the relevance of that content in their current professional positions. Data obtained from pre and posttests administered to the participants before and after the mentorship program reflected the significant effectiveness of the intervention in the classroom, socially among peers, and in the field (placement and work site). While the quantitative data supported the efficacy of the project, it was narrowly focused on outcomes and did not allow for the participants to share their lived experiences. This qualitative project was implemented through eight open-ended questions, explored in an interview format, lasting between 20-50 minutes.

\subsection{Procedure}

The Internal Review Board (IRB) process was completed and outreach to participants was initiated upon agreement to participate via the professor who managed the original mentorship project. Nine individuals from the original study expressed interest in a follow up interview; five responded with verbal permission to be interviewed.

\section{Results}

Thematic content analysis was used to identify common concerns shared by participants (Crowe, Inder \& Porter, 2015). Participants stated that their top concerns prior to joining the mentorship program included: assistance with writing, support from professors and peers, feeling unsafe in the program, wanting more from the program, and contemplating quitting the MSW program, with peers and mentors encouraging them to stay. The two most significant themes that were found in every participant's narrative in relation to participation in the mentorship program were a) Effective interventions and b) Challenges in implementation.

\subsection{Effective Interventions}

Participants overwhelmingly felt the mentorship program benefited them while in the MSW program and after graduation, citing writing assistance, support from faculty and peers, and the feeling of having a safe space where they could discuss various issues and vent about their struggles with like-minded people as the most salient elements of the program.

All of the participants stated that they felt the writing support from the mentorship program was one of the most effective interventions of the project. One participant stated that, "I guess [writing] was one of the reasons that they had done [developed] the mentorship [project], because a lot of people were struggling with.....the change. Not the change [to writing], but the styles of writing [from professional to academic writing]" (Participant \#02). Participated \#01 asserted the writing support and guidance was helpful because, "I had been out of school for quite some time; my previous degree was in 2006, so when I returned [to graduate school] it had been probably almost 10 years." Participant \#03 reported, "I was out of school for a long time, 30 years, and so I imagined that I would need some help, and so when they [mentorship program faculty] explained their purpose, I thought, oh this is great". Participant \#01 found that while the writing support was significant, professional support overall was essential, acknowledging that:

"Writing-wise, we would just kind of support each other. Let each other know if we felt we were on the right track, things like that. But of course, I would count on the professors for the final say on whether I was okay or not. I just enjoyed it".

The support of peers was found to be highly beneficial, and participants reported the ability to connect with other participants with similar experiences and challenges made an impact on how the mentorship program influenced them.

All of the participants reported feeling supported by both faculty and peers within the mentorship program. This support was in direct contraction with the lack of support they felt with their cohorts and faculty in the larger MSW program pre-mentorship program involvement, and influenced their openness to joining the mentorship program. Feeling supported and validated also impacted these students' retention rates. Participants \#01, \#02, \#03 and \#04 all indicated that they contemplated quitting the MSW program, but did not, largely due to encouragement from other participants. While family members and colleagues also encouraged staying in the program, the support of peers 
managing the same challenges with the same perspective appeared to be critical.

Each of the participants identified their own intersectional identities as factors impacting their struggles. The majority of the participants self-identified as female ( $3=$ female, or $60 \%)$, and all of them identified as non-white with a marginalized ethnic identity. Interestingly, all of the female participants contemplated quitting the MSW program and the only person to quit the mentorship program were women, consistent with the literature that cites women re-entering academic programs as having additional needs and challenges to successful academic promotion and graduation. Peers support encouraged three out of the four contemplating quitting the program to stay both in the MSW program and the mentorship program, while one of the participants continued in the MSW program but quit the mentorship program. Participant \#05 even stated that, "They [faculty] gave [us] tips and that was helpful, and it feel[t] much more relaxed, because it was not a classroom setting. They weren't grading us or anything. It was more supportive, and it helped [us]".

Finally, it was unanimously reported that the mentorship program provided a safe environment where participants felt comfortable expressing themselves to discuss challenges at school, and at their places of employment (County Child Welfare), with internship placements, and with family. Participant \#05 detailed that:

"we felt like it was safe place for us to talk, even about other instructors, and about work, and Professor [Jane], Professor [Doe], they were [from the County Child Welfare Agency], so they kind of understood what we were going through. When we talked about something, [County Child Welfare Agency]-related stuff, they understood a little bit. So, we [could] talk about [the County Child Welfare Agency], internships, school, everything."

Another participant (\#04) asserted "It [was] a safe environment, a safe place."

\subsection{Challenges of Implementation}

Although the program was largely experienced positively, the participants also noted challenges and deficits with the mentorship program. A primary issue identified by almost all the participants was that the time of the mentorship program was not congruent with their schedules. Because the program was mandatory, when the semester became stressful (ie midterms, finals), the stress in managing multiple role conflicts made the program less valuable and beneficial. The participants noted that they maintained responsibility for school, their DCFS employment and their families, which created conflicting interests when trying to fit in time for the mentorship program. Participant \#04 reported that,

"I think the hardest [issue] was the pressure that we had to meet at this time at this place, it added more to our school [responsibilities]. The addition of something else on top of the schooling....If we spread ourselves too thin and then [they are] like 'Oh, here's another one, do the mentorship program for you, we have to leave at this time' and [the County Child Welfare Agency] was like 'Well, you can't do that, that's on county time.' So, it was a time of exploring it at the time, so we had to kind of be creative as far as, well maybe we could skip our lunch. Some people reacted differently about it...I think that was the biggest [issue], those mentorship meetings were mandatory. I think that should have been removed; it could have been more voluntary".

Participants indicated that they would have liked additional tools to improve clinical skills, noting that even when they were presented there wasn't enough time or explanation regarding how to utilize them. They expressed that more detailed explanation of various handouts that were presented would have been helpful. Participant \#02 stated:

"There was no clinical work. Maybe that wouldn't be bad ... maybe including some of the clinical ... I know that we have it in classes sometimes, but maybe including some of the clinical writing would be good".

Another participant (\#03) stated that:

"I thought that there could have been more handouts, more activities. Then [they] went on to discuss them. I felt when they gave [handouts] I was like, this is it? You know, that was kind of my attitude."

\section{Discussion}

The interviews shed light on the positive impact a mentorship program can have on individuals within it. Participants clearly extolled the virtues of mentorship with working students re-entering academic environments, including writing support, professional and personal support, and a safe environment. The data collected indicated that participants benefitted most from writing support and social connectedness with the group. Narratives from the participants reflected strengths in the relational approach the faculty took to working with the students, allowing for them to feel supported and to belong. Peer support as well contributed to the experience of validation, increasing 
program retention rates.

There are multiple studies that address the challenges faced by CSW's working at County Child Welfare agencies who enroll as students in MSW programs. This research outlines the struggles of CSW's as different than 'traditional' graduate students (Bauman, Wang \& DeLeon, 2004; Hall \& Sudol, 1991). CSW/MSW students face barriers with academic writing requirements and with shifting their perspectives from being a professional social worker (as a title) to being a social work student (as a discipline) (Michaud, 2011). Additional factors such as age, income, cohort connectedness, and application of life experiences to the classroom environment, all add complexity to their adjustment (Hall \& Sudol, 1991).

The narratives collected were consistent with the needs of returning students in the literature, and participants clearly addressed the ways they benefitted from the project as well as ways they felt the mentorship program could be improved. The participants' intersectional identities appeared to play a crucial role in how they interacted with academic colleagues prior to the mentorship program, with peers and faculty within the mentorship program, and what they ended up taking from it when it concluded. Because most of the participants who considered quitting the MSW program and/or the mentorship program identified as female reflects a vital need for extra support for female students returning to graduate programs.

\section{Limitations and Future Research}

This study was limited by the number of participants and the context. Five participants reflect a very small sample size; thus, the results cannot be generalized and no definitive conclusions can be made. In addition, the study was limited to participants from a single child welfare agency, one mentorship project and from one four year university. This is not inclusive of other agencies, other universities, other mentorship programs and the different experiences that might be found in other locations. Further, the participants engaged in the mentorship program for varying amounts of time, impacting both their experience of the program and their narrative regarding its costs and benefits.

Future research would benefit mentorship program development by expanding the participant count and location, allowing for a larger sample size and narrative input. It would also assist future mentorship programs to acknowledge the intersectional identities that each participant has in order to better understand their needs and challenges. This may identify specific intervention strategies to support nontraditional child welfare (and other) students returned to graduate programs and clarify the extended support various populations may require for successful promotion, graduation and application of skills post-graduation.

\section{Conclusion}

The purpose of this research study was to explore if implementation of a mentorship program for County Child Welfare Social Workers (CSW's) obtaining a Master of Social Work (MSW) degree contributed to student success post-graduation when returning to public child welfare employment. Participant narratives included beneficial information, skills and knowledge as well as critiques on what they did not learn or receive from the mentorship program. Participants consistently identified writing support and guidance, support and connection from professors and peers, experiencing a safe environment, and support to decide whether they would continue their MSW program as primary benefits from the mentorship program. Critiques centered on individual needs (for clinical depth and explanation) as well as challenges with the timing of the program and the mandatory expectation of attendance.

The data collected from the small sample can lead towards further research to better implement and structure mentorship programs for County Child Welfare Social Workers pursuing higher education. There is a dearth of research reflecting the experiences of CSW's, minimal data on mentorship programs for the population, and even less information chronicling the experiences of CSW's post master's degrees. The participants in this study described the challenges they faced returning to graduate school, illuminating the importance of mentorship and support for academic, interpersonal and professional success. If academic settings further develop suitable mentorship programs for CSW's returning to obtain their MSW, there will a better chance of having more graduate level professionals working in County Child Welfare Agencies with the skills to effectively represent and protect the vulnerable children and families within the system.

\section{References}

Allen, T. D., Eby, L. T., \& Lentz, E. (2006). Mentorship behaviors and mentorship quality associated with formal mentoring programs: Closing the gap between research and practice. Journal of Applied Psychology, 91(3), 567-578. https://doi.org/10.1037/0021-9010.91.3.567

Barth, R. P., Chapman, M. V., Christ, S. L., Dickinson, N. S., \& Lloyd, E. C. (2008). Child welfare worker 
characteristics and job satisfaction: a national study. Social Work, 53(3). https://doi.org/10.1093/sw/53.3.199

Bauer, D., \& Mott, D. (1990). Life themes and motivations of re-entry students. Journal of Counseling \& Development, 68(5), 555-560. https://doi.org/10.1002/j.1556-6676.1990.tb01410.x

Bauman, S., Wang, N., \& DeLeon, C. (2004). Nontraditional students' service needs and social support resources: A pilot study. Journal of College Counseling, 7(1), 13. https://doi.org/10.1002/j.2161-1882.2004.tb00254.x

Cleary, M. (2012). Anxiety and the newly returned adult student. Teaching English in the Two-Year College, 39(4), 364-376.

Crowe, M., Inder, M., \& Porter, R. (2015). Conducting qualitative research in mental health: Thematic and content analyses. Australian \& New Zealand Journal of Psychiatry, 49(7), 616-623. https://doi.org/10.1177/0004867415582053

Elliott, R. (1999). Editor's introduction to special issue on qualitative psychotherapy research: Definitions, themes and discoveries. Psychotherapy Research, 9, 251-257. https://doi.org/10.1080/10503309912331332741

Fleming, T., \& Murphy, M. (2000). Between common and college knowledge: Exploring the boundaries between adult and higher education. Studies in Continuing Education, 22(1), 77-93. https://doi.org/10.1080/713695718

Gigliotti, R., \& Huff, H. (1995). Role-related conflicts, strains and stresses of older-adult college students. Sociological Focus, 28(3), 329-342. https://doi.org/10.1080/00380237.1995.10571057

Gillam, A. M. (1991). Returning Students' Ways of Writing: Implications for First-Year College Composition. The Journal of Teaching Writing, 10(1), 1-20.

Hall, A. M., \& Sudol, D. (1991). Back to School: Warnings and Advice to the Older Graduate Student. Paper presented at the Annual Meeting of the Conference on College Composition and Communication, (42nd, Boston, MA, March 21-23, 1991).

Home, A. (1998). Predicting role conflict, overload and contagion in adult women university students with families and jobs. Adult Education Quarterly [H.W. Wilson - EDUC], 48, 85. https://doi.org/10.1177/074171369804800204

Manzo, D., \& Ross-Gordon, J. (1993). Socialization Outcomes of Part-time Master of Social Work Programs: A Comparison of Returning Adult Students in Career Transition with Returning Adult Students with Undergraduate Training and Practical Experience in Social Work. n.p.: ProQuest, UMI Dissertations Publishing.

Michaud, M. (2011). The "reverse commute": Adult students and the transition from professional to academic literacy. Teaching English in the Two-Year College, 38(3), 244-258.

Padula, M. (1999). Understanding graduate women's reentry experiences: Case studies of four psychology doctoral students in a midwestern university. Psychology of Women Quarterly, 23(2), 327. https://doi.org/10.1111/j.1471-6402.1999.tb00364.x

Padula, M. A. (1994). Reentry women: A literature review with recommendations for counseling and research. Journal of Counseling and Development: JCD, 73(1), 10. https://doi.org/10.1002/j.1556-6676.1994.tb01703.x

Stoecker, J. (1991). Factors influencing the decision to return to graduate school for professional students. Research in Higher Education, 32(6), 689-701. https://doi.org/10.1007/BF00974738

The Social Work Gender Gap - MSW Careers. (2016, December 20). Retrieved April 06, 2018, from https://mswcareers.com/social-work-gender-gap/

Watts, J. (2009). From professional to Ph.D. student: Challenges of status transition. Teaching in Higher Education, 14(6), 687-691. https://doi.org/10.1080/13562510903315357

Westervelt, E. M. (1975). Barriers to Women's Participation in Postsecondary Education. A Review of Research and Commentary as of 1973-74. (United States, U.S. Department of Health, Education, and Welfare). Retrieved from https://eric.ed.gov/?id=ED111256 